\title{
Interactions Across Firms and Bid Rigging
}

\author{
Mats A. Bergman ${ }^{1} \cdot$ Johan Lundberg ${ }^{2}$. Sofia Lundberg ${ }^{2} \cdot$ Johan Y. Stake $^{3}$ \\ Published online: 4 January 2019 \\ (C) The Author(s) 2019
}

\begin{abstract}
We evaluate whether an econometric technique that is used in the spatial econometrics and network effects literatures can be adopted as a test for collusive bidding in public procurement auctions. The proposed method is applied to the Swedish asphalt cartel that was discovered in 2001. Our dataset covers the period 1995-2009, which makes it possible to test for conditional independence between complementary cartel bids before and after 2001. Our estimates show a significant positive correlation between complementary cartel bids during the cartel period, whereas a non-significant correlation is shown during the later period. The variance of the parameter estimate of interest also differs between the periods, which suggests a structural change in bidding behavior among cartel members between the two periods.
\end{abstract}

Keywords Antitrust - Auction - Cartel and collusion - Complementary bidding · Public procurement $\cdot$ Networks $\cdot$ Spatial econometrics

JEL Classification D44 $\cdot \mathrm{H} 57 \cdot \mathrm{L} 10 \cdot \mathrm{L} 40$

\section{Introduction}

Early on October 24, 2001, the Swedish Competition Authority (SCA) conducted unannounced raids on a number of companies in the Swedish asphalt paving industry; the purpose was to find documents that could verify suspicions of illegal collusive bidding on public contracts. ${ }^{1}$ In 2003, nine firms were convicted for collusive

\footnotetext{
${ }^{1}$ Documentation from the SCA (Swedish Competition Authority 2009) suggests that the asphalt cartel began operating in 1993. The four largest companies in the asphalt paving industry met secretly several times per year. At these meetings, the companies agreed on how to divide state, municipal, and private contracts among themselves and also exchanged information on prices and volumes. Companies that

Johan Lundberg

johan.lundberg@umu.se

1 Department of Economics, Södertörn University - Stockholm, 14189 Huddinge, Sweden

2 Department of Economics, Umeå School of Business and Economics, Umeå University, 90187 Umeå, Sweden

3 The Swedish Post and Telecom Authority, Box 5398, 10249 Stockholm, Sweden
} 
bidding in the Stockholm District Court. The convicted firms appealed the decision to the Market Court, which confirmed the District Court's decision on July 10, 2007.

Based on data on public procurements of asphalt paving before and after the raids in 2001, the main objective of this paper is to show how an econometric method that is influenced by the spatial econometric literature (see Anselin 1988; Anselin and Bera 1998; LeSage and Pace 2009; Gibbons et al. 2015) ${ }^{2}$ can be used to confirm collusive bidding before the raids in 2001 and reject such behavior during a period after the first court order in 2003. Following Gibbons et al. (2015) spatial data consists of observations located in some space. In this paper the unit of observation is the bid and the space is the specific auction, which places our approach in the class of spatial models that are often applied on social networks. The access to data after the cartel members were convicted constitutes a good testing ground for the suggested method and at the same time for the efficacy of litigation in stopping the collusion.

The parameter of interest in the empirical model can be interpreted as the slope of reaction curves between firms that place bids on the same contract. This follows broadly the same principle as in Bajari and Ye (2003): That in the absence of collusive bidding and after controlling for publicly available information, bids placed by one firm should be uncorrelated with bids placed by all other firms. ${ }^{3}$

Our results indicate collusive bidding among cartel members before 2002, while the relevant parameter is insignificant, and its variance differs in magnitude after 2003-which is consistent with non-collusive bidding. This suggests a structural change in bidding behavior among cartel members between the cartel and post-cartel periods and, hence, that the litigation caused the cartel to cease its activities.

We argue that our approach—given some prior ${ }^{4}$ on where to look for suspicious behavior-can be used to corroborate cartel suspicions. The method is relatively simple; it requires only a minimal amount of data. If this method shows significant dependence of bids among a group of suspected bidders while insignificant and different dependence across the other bidders, competition authorities could decide to proceed with further investigations.

To our knowledge, spatial econometrics techniques have never before been used to test for collusion in the way that is proposed in this paper. The advantage of our suggested approach is the applicability to various auction designs, the modest data

\footnotetext{
Footnote 1 (continued)

were not included in the group — and thus potential competitors - were compensated for abstaining from bidding or placing uncompetitive bids. Hence, in practice, the cartel involved all or almost all firms.

2 Spatial econometric methods are traditionally applied in fields of economics such as public economics, local public finance, and agricultural and environmental economics (Anselin 2003). The similarities between our approach and spatial econometrics is the weight matrix W to be explained below. However, the same approach can be used in, for instance, analyses of network effects. Gibbons et al. (2015) is a good overview of spatial econometrics and its use in both regional science, where the degree of connection between different agents (jurisdictions, municipalities, companies, etc.) are typically based on the geographical distance, and social networks, where the degree of connection may, for instance, depend on the social hierarchy within the network.

3 Unless there are unobserved variables that cause correlation.

4 The prior could, for example, be based on factors that characterize markets that are typically conducive to cartel formation (Harrington 2008) and, in these markets, focus on the dominant bidders.
} 
requirement, and the simple estimation techniques - as compared to tests that have been used previously. This paper also serves as a complement to previous studies that, for the most part, are based on U.S. data and from the cartel period only.

Two limitations - which we share with the vast majority of the existing literature on cartel detection-are that: (1) the investigator needs a relatively specific hypothesis with respect to which firms are involved in the cartel; and (2) the competition authority will need accompanying evidence for a charge to hold up in court. See Harrington (2008) and Abrantes-Metz and Bajari (2009) for surveys.

The rest of this paper is organized as follows: Sect. 2 provides an overview of the existing literature; it is followed in Sect. 3 by a description of the procurements studied. Section 4 presents our data, and the econometric setup and specification are presented in Sect. 5. The results are presented and discussed in Sect. 6, with concluding remarks provided in Sect. 7.

\section{Previous Literature}

Collusive behavior can take many forms and occurs in markets with posted pricing, bargaining, or bidding. We focus this discussion on the literature that deals with bidding markets and procurement auctions. Furthermore, following Harrington (2008), a distinction can be made between two broad approaches for cartel discovery: The first-also known as cartel prediction-is a structural approach that seeks to identify markets with characteristics that are typically conducive for cartel formation, such as few rivals and homogenous products. The second-cartel detection-is a behavioral approach that tries to identify suspicious patterns of behavior, which could be either direct evidence of communication, such as illicit meetings and messages, or patterns in prices and quantities that indirectly reveal collusion.

While direct evidence of communication is the foundation of law enforcement against cartels, the empirical economics literature on cartels has mainly centered on cartel detection by means of statistical analysis of patterns in bidding or pricing. Bajari and Summers (2002), Harrington (2008), Abrantes-Metz and Bajari (2009) and Doane et al. (2014) survey this strand of the literature, while Grout and Sonderegger (2005) discuss market characteristics that make cartel formation more likely and how the existence of cartels can be predicted from such characteristics.

The empirical literature on cartel detection can be further divided into two categories: One category of studies includes instances where the investigator has prior knowledge or suspicions as to the identity of the cartel members and where the challenge is to verify econometrically the cartel's existence (e.g., Froeb et al. 1993; Porter and Zona 1993, 1999; Lee 1999; Pesendorfer 2000; Lee and Hahn 2002; Gupta $2001,2002)^{5}$; the other category of studies involve screens for collusive behavior without prior knowledge of collusive behavior (e.g. Bajari and Ye 2003; Ishii 2009; Kawai and Nakabayashi 2014; Conley and Decarolis 2016).

\footnotetext{
5 See also Cramton and Schwartz $(2000,2002)$ for papers on spectrum auctions.
} 
Our study lies mainly in the first-mentioned tradition. However, the distinction between screening and verification is blurred, as the strength of the suspicions can vary continuously. Hence, following Harrington (2008), cartel detectionwhether for screening or verification-can be classified according to the method that is used. Harrington distinguishes between four main approaches: (1) tests of whether actual behavior is significantly different from that which should follow from competitive behavior; (2) tests for a structural break in behavior, which could, for example, mark the formation or demise of a cartel; (3) tests of whether the behavior of a set of firms, suspected of having formed a cartel, differs from that of other firms; and (4) tests of whether a collusion model better describes the data than does a competitive model. Because the method we propose is similar in spirit both to the second and the third categories, we briefly review some of the studies in these traditions.

Abrantes-Metz et al. (2006) find a structural break, as price variance increased around the time that a known cartel collapsed; they apply a similar test to a large sample of firms. Porter and Zona (1993) estimate a bid equation for three sets of firms: for those suspected of having formed a cartel; for the remaining firms; and for all firms jointly. They subsequently apply a Chow test to the null hypothesis that the estimates are the same for the two subsets and the full set, and they are able to reject the null hypothesis. The implication is that the suspected cartel members bid in a way that is significantly different from how other firms bid and that this is an indication of collusion that strengthens the initial presumption.

A third study that uses a related method—also by Porter and Zona (1999)—estimates a bid equation where the slope coefficients (and the intercept) are allowed to differ between the suspected cartel firms and the presumably innocent outsiders. If the coefficients differ significantly — and in a way that is consistent with collusionthis will again serve to strengthen the initial suspicions of collusion.

Bajari and Ye (2003) depart from the hypothesis that under non-collusive bidding and after controlling for relevant attributes of the firms, bids should be statistically independent. Bids should thus fulfil two criteria: conditional independence (bids placed by different firms should be statistically independent when controlling for all factors that affect production costs that are known to the firms); and exchangeability (after controlling for factors that determine costs, bids that are placed by one bidder should be statistically independent of the identity of competing bidders).

Statistical independence is also the main ingredient in the empirical approach that is suggested in the current paper, although with a different estimation technique. Traditionally, the spatial dimension is geographical (e.g., Heijnen et al. 2015); but here we apply it to the bidding environment with strong similarities to the class of spatial models that Gibbons et al. (2015) define as social interaction models. The space is the bidding environment, and the data consist of the submitted bids. The interaction of main interest is that among bidders. More specifically, we focus on the interdependence across the cartel members' bids during and after the cartel period, respectively, and on how this interdependence differs between the two periods. Our approach adds to tests that have previously been presented in the literature by 
allowing for variety in auction design, the modest data requirement, and the simple estimation techniques. ${ }^{6}$

\section{Road Pavement Procurement}

The Swedish Road Administration (SRA) ${ }^{7}$ is responsible for the construction, operation, and maintenance of national roads; this makes the SRA a frequent buyer of road pavement for construction and repair. During the period for which we have data-1995 to 2009 - the SRA had seven autonomous district organizations with responsibility for road maintenance within their respective geographical areas. The SRA publishes most of its calls for tenders for the road-pavement contracts early in the spring, and the works are mainly undertaken during the summer months. The bidders are allowed to use each other as subcontractors, which makes capacity constraints less of a concern in our analysis.

Following the general principles for public procurement within the EU, ${ }^{8}$ the SRA uses competitive bidding to allocate the contracts: usually in a first-price sealed-bid auction. ${ }^{9}$ The conditions of the auction and the contract specifics are stipulated in the call for tender. A single road-pavement procurement auction may include several contracts; and, if it does, bidding is simultaneous, and firms may submit bids for all, or for a subset, of the contracts.

Potential bidders are allowed to submit one bid per contract that is auctioned in the same procurement, and the submitted bids are opened and evaluated simultaneously. A typical road-pavement call for tender stipulates the road section, the amount of asphalt to be procured and the quality, other contract conditions, and principles for supplier selection. Except for a few combinatorial-bid procurements, which are discussed below, the bids for a specific contract are evaluated independently of bids

\footnotetext{
${ }^{6}$ Heijnen et al. (2015) is a recent attempt to screen for cartels without a prior as to the identities of the firms. In a first stage they select the firms with the lowest price variation; and in a second step they analyze whether some of the selected firms are more geographically clustered than would be expected by pure chance. Kawai and Nakabayashi (2014) propose a method with similarities to the regression discontinuity approach that can also be used without prior knowledge. The procurement auctions they study are potentially held in consecutive rounds. If a secret reservation price is not met in the first round, the auction moves to a second (and potentially a third) round. Before the second round starts, the lowest bid-but neither the reservation price nor the identity of the lowest bidder-is revealed. The special feature of this design and the statistical expectations of bid ranking and winning probabilities are used to detect anomalies. Conley and Decarolis (2016) study the effect on entry (from potential cartel members that are designated not to win the contract) when an Italian authority shifted from the so-called AverageBid-Auction (ABA) to a classical reverse first-price sealed-bid auction. Again, the method can be applied without having a particular set of suspected bidders.

7 Since 2010, the Swedish Transport Administration. For more information, see www.trafikverket.se. Accessed online July 7, 2016.

8 Directives 2014/25/EU and 2014/24/EU.

9 This format is less vulnerable to collusion than the second-price sealed-bid auction and the English auction. The reason is that under the first-price sealed-bid auction it is more difficult for cartel members to monitor each other (see e.g., Börgers and van Damme 2004) and it involves stronger incentives for cartel members to deviate from the cartel agreement (Robinson 1985).
} 
for other contracts that are tendered in the same procurement. After the contracts are signed, the bids and evaluation protocol are made public.

The allocation of contracts can (in principle) be based either on lowest price in combination with mandatory quality criteria or on the economically most advantageous tender (EMAT); see e.g., Bergman and Lundberg (2013). The use of EMAT gives the procurement the character of a multidimensional auction (e.g., Che 1993), which is normally combined with mandatory criteria. In the auctions that we studied, a clear majority of the contracts were allocated to the lowest bidder (Jakobsson 2007a, b). A few procurements allowed combinatorial bids: package bids with rebates conditional on the number of contracts that were won or limits on how many contracts a given firm can accept (see e.g., Lunander and Lundberg 2013). As combinatorial bidding strategies in comparison with the standard auction are relatively complex, auctions with combinatorial bids are excluded from the analysis.

Within the EU, different procurement procedures are allowed: The design may vary in that respect. If the total value of the procurement is below the threshold value of 5,225,000 euro, ${ }^{10}$ the procurer can use a simplified procedure that is open for all bidders, and the procuring authorities have the opportunity to initiate negotiations with some of the bidders. ${ }^{11}$ For procurements above the threshold, the open procedure is, in similarity to the simplified procedure, open to everyone, while the rest of the procedures (negotiated and restricted) all have some limitations in bidding, e.g., firms must qualify in order to be given the opportunity to bid. ${ }^{12}$ For purchases of relatively low value, authorities are allowed to use a less formal auction format or a so-called direct procurement. ${ }^{13}$ Procurements above the threshold value have to be announced in the Official Journal of the European Union. ${ }^{14}$ No non-Swedish firms are observed in our data.

\section{Data}

The datasets that are used in this study originate from three sources: the Swedish Road Administration (SRA); Statistics Sweden (SCB); and the Swedish Meteorological and Hydrological Institute (SMHI).

Our data for individual procurements were compiled from SRA documents and contain information on 427 SRA procurements of paving and asphalt works:

\footnotetext{
10 See Directive 2004/17/EG. Note that in 2009, EUR 1 was approximately SEK 10.62, and USD 1 was SEK 7.65; while as of July 7, 2018, one euro is 10.99 SEK, and one dollar is 9.41 SEK.

11 The threshold value was for the cartel period 5,000,000 euro and for the period after the cartel was detected 5,225,000 euro.

12 See http://europa.eu/youreurope/business/public-tenders/rules-procedures/index_en.htm for more information. Accessed online June 22, 2015.

13 See e.g. Lundberg (2005) for more on procurement procedures.

14 See http://ted.europa.eu/TED/main/HomePage.do. Accessed online July 11, 2016.
} 
specifically, surfacing works ${ }^{15}$ between 1995 and 2009. ${ }^{16},{ }^{17}$ The data are based on procurement documents such as the call for tender and the decision records: including the bids and the identity of the bidding firm collected from SRA offices. As it is possible that the companies under investigation did not directly realize the seriousness of the charges, or that the bidding behavior that had been established within these firms persisted for some time despite efforts to reform, we allow them two years to adapt to these new conditions; hence, we exclude data between the raids in 2001 and the first court order in 2003. ${ }^{18}$

In total, the dataset contains information on 232 procurements, with 427 contracts and 2129 bids that were submitted by 58 individual firms. Descriptive statistics for the variables are displayed in Table 1.

Our dependent variable, $b_{i}$, is measured as the bid in SEK per square meter of paving. ${ }^{19}$ Optimally, we would use asphalt measured in tons because there are variations in how thick the layer of new asphalt is, and the use of square meters could therefore reduce the precision of our estimates. However, because we use only data on relatively non-complex asphalt and paving works (only surfacing), we believe this to be a minor problem.

From Table 1, the observed mean of the bid per square meter is significantly higher at the 10-percent level of significance ${ }^{20}$ during the cartel period, which is expected; this is also the case for the weighted mean. With complementary bid$\operatorname{ding}^{21}$ a larger difference between the lowest (designated winner) and second lowest cartel bid may be expected. However, as shown in the lower part of Table 1, the relative difference between the second lowest and lowest cartel bid is higher during the post-cartel period. As the cartel involved all of the firms (even though only nine of them were convicted), one potential explanation is that during the cartel period, cartel members did not bid in accordance with their marginal cost but instead based on administrative agreements within the cartel, as was revealed by the SCA investigation (Swedish Competition Authority 2009). The relative difference between all cartel bids (but the lowest) and the lowest cartel bid is lower during the cartel period.

For the post-cartel period, the number of bidders is 4.26 per contract on average-down from 5.61 during the cartel period; this is a statistically significant ${ }^{22}$ difference. The average number of bids by convicted cartel members on each contract declined from 3.63 during the cartel period to 2.81 for the later period.

\footnotetext{
15 Common Procurement Vocabulary (CPV) code 45233222-1.

16 Data for most of the first period (the cartel period) were previously used in Jakobsson (2007a, b), while data for the post-cartel period as well as for the final two years of the cartel period were compiled more recently.

17 When a public contract is signed, all procurement documents become public records. The data are based on the call for tender including the bids, technical specification, and decision protocol.

18 This has also been discussed with officials at SCA.

19 All prices are at the 2009 price level.

20 Two-sample $t$ test with unequal variances give a $t$-value of $1.79((\operatorname{Pr}|T|>|t|)=0.074)$.

${ }^{21}$ Complementary bidding occurs when a cartel member places an artificially high bid without the ambition to win the contract but with the purpose to create the appearance of competitive bidding. The concept is also referred to as courtesy bidding or cover bidding.

22 Two-sample $t$ test with unequal variances give a $t$-value of $19.21((\operatorname{Pr}|T|>|t|)=0.000)$.
} 
Complementary bidding is a possible explanation; but lower profitability during the post-cartel period could also have resulted in fewer firms' being willing to incur the cost of bidding.

As pointed out by (among others) Bajari and Summers (2002), it is important to control for other factors that are likely to affect the cost of completing the contract. Therefore, the size of the contract measured in square meters of asphalt $\left(\right.$ Area $\left._{c}\right)$ is used to control for potential economies of scale for individual projects.

It is also reasonable to assume that the number of potential bidders (or the degree of competition) has a negative effect on $b$. However, information on potential bidders is not easily collected. The number of actual bidders on a specific contract or the number of existing firms within the region where the contract is issued are potential candidates. ${ }^{23}$ These measures are, however, potentially problematic:

First, a firm that is located in a particular region may not be interested in bidding (or have the capacity to bid) for all contracts in that region, while firms located outside of that region may be interested. Second, according to the court order, the cartel included all firms in the market. This makes measures such as the number of actual bids and the potential number of bidders likely to capture complementary bidding behavior instead of the degree of competition. Third, the number of actual bidders is endogenous in relation to $b$, and relevant instruments are not easily found. Here, we use dummy variables for procurement procedure (direct, negotiated, restricted, open, simplified, and selective) as instruments in the models where the actual number of bidders, Comp $c$, is included. However, as valid instruments for Comp are not easily found, we present results both with and without Comp. ${ }^{24}$

Table 2 shows how frequently the different procedures appear in the data, the share of contracts by year, the geographical region, and the type of procurement procedure. The majority of the procurements have a value below the EU threshold; consequently, the simplified procedure is the most commonly applied procedure: used for 74 and 93 percent of the procurements for the two time periods, respectively.

As shown in Table 2, there is substantial variation in the share of contracts across districts. $^{25}$ The northern region accounts for only 9 percent in the earlier period but for more than 50 percent in the latter. The reasons for the large increase for the northernmost region is that the data from 1995 to 1999 includes only regions 3-7, whereas the data from 2000 and on include procurements from all regions_-although with a

\footnotetext{
${ }^{23}$ We have re-estimated our models with data on the number of recorded firms-denoted Pcomp in Table 1-within this industry for the different regions. As it turned out, the number of recorded firms are a poor predictor of $b$. This is likely since the number of recoded firms range between 68 and 192 and does not vary much over regions and time, while the actual number of bidders ranges between 2 and 10 and varies across contracts.

24 As pointed out by Bound et al. $(1993,1995)$, the "cure can be worse than the disease" when the excluded instruments are only weakly correlated with the endogenous variables.

25 The seven regions are (1) North (county of Norrbotten and Västerbotten), (2) Middle (county of Jämtland, Västernorrland, Gävleborg, and Dalarna), (3) Stockholm (county of Stockholm and Gotland), (4). Mälardalen (county of Uppsala, Västmanland, Södermanland, Örebro and Östergötland), (5) West (county of Värmland, Västra Götaland and Halland), (6) Southeast (county of Blekinge, Kalmar, Kronoberg, and Jönköping) and (7) (county of Skåne).
} 
Table 1 Descriptive statistics

\begin{tabular}{|c|c|c|c|c|}
\hline & Mean & Std. dev. & Min & Max \\
\hline \multicolumn{5}{|l|}{ Whole sample, 1995-2009 } \\
\hline Bid, SEK per square meter $(b)$ & 1630.6 & 7685.1 & 6.19 & $92,161.5$ \\
\hline Square meters per contract $\left(\right.$ Area $\left._{c}\right)$ & 55,386 & 71,701 & 160 & 607,613 \\
\hline Competition; No of bids $\left(\right.$ Comp $\left._{c}\right)$ & 5.42 & 1.50 & 2 & 10 \\
\hline Potential number of bidders $\left(\right.$ Pcomp $\left._{c}\right)$ & 107.42 & 30.95 & 68 & 192 \\
\hline Population density, pop per $\mathrm{km}^{2}\left(\right.$ Dens $\left._{r}\right)$ & 64.55 & 62.43 & 3.29 & 196.9 \\
\hline Average temperature, Celsius $\left(\operatorname{Temp}_{c}\right)$ & 6.00 & 2.31 & 0.35 & 9.68 \\
\hline Average rainfall, millimeter $\left(\operatorname{Rain}_{c}\right)$ & 56.41 & 12.65 & 29.43 & 81.89 \\
\hline Number of contracts & 427 & & & \\
\hline Observations & 2129 & & & \\
\hline \multicolumn{5}{|l|}{ 1995-2001 (cartel period) } \\
\hline Bid, SEK per square meter $(b)$ & 1717.2 & 8036.8 & 12.1 & $92,161.5$ \\
\hline Square meters per contract $\left(\right.$ Area $\left._{c}\right)$ & 47,937 & 61,138 & 160 & 607,613 \\
\hline Competition; No of bids $\left(\operatorname{Comp}_{c}\right)$ & 5.61 & 1.47 & 2 & 10 \\
\hline Potential number of bidders $\left(\right.$ Pcomp $\left._{c}\right)$ & 108.68 & 31.49 & 68 & 167 \\
\hline Population density, pop per $\mathrm{km}^{2}\left(\right.$ Dens $\left._{r}\right)$ & 72.28 & 63.47 & 3.30 & 196.91 \\
\hline Weighted average, $\frac{\sum \text { winningbidinSEK }}{\sum \text { squaremeterspercontract }}$ & 182.66 & & & \\
\hline Average temperature, Celsius $\left(\right.$ Temp $\left._{c}\right)$ & 6.39 & 1.96 & 0.36 & 9.65 \\
\hline Average rainfall, millimeter $\left(\operatorname{Rain}_{c}\right)$ & 56.31 & 13.28 & 29.43 & 81.89 \\
\hline Number of contracts & 352 & & & \\
\hline Observations & 1830 & & & \\
\hline \multicolumn{5}{|l|}{ 2004-2009 (post-cartel period) } \\
\hline Bid, SEK per square meter $(b)$ & 1100.4 & 4999.5 & 6.19 & 39,300 \\
\hline Square meters per contract $\left(\right.$ Area $\left._{c}\right)$ & 100,978 & 106,513 & 170 & 601,625 \\
\hline Competition; No of bids $\left(\right.$ Comp $\left._{c}\right)$ & 4.26 & 1.06 & 2 & 7 \\
\hline Potential number of bidders $\left(\right.$ Pcomp $\left._{c}\right)$ & 99.71 & 26.22 & 76 & 192 \\
\hline Population density, pop per $\mathrm{km}^{2}\left(\right.$ Dens $\left._{r}\right)$ & 17.26 & 22.15 & 3.29 & 108.76 \\
\hline Weighted average, $\frac{\sum \text { winningbidinSEK }}{\sum \text { squaremeterspercontract }}$ & 121.57 & & & \\
\hline Average temperature, Celsius $\left(\operatorname{Temp}_{c}\right)$ & 3.63 & 2.85 & 0.67 & 9.68 \\
\hline Average rainfall, millimeter $\left(\operatorname{Rain}_{c}\right)$ & 57.03 & 7.68 & 45.32 & 75.72 \\
\hline Number of contracts & 75 & & & \\
\hline Observations & 299 & & & \\
\hline $\begin{array}{l}\text { Statistics for bid per sqm (SEK/sqm)_cartel } \\
\quad \text { members only }{ }^{\mathrm{a}}\end{array}$ & 1995-2001 & & 2004-2009 & \\
\hline$\frac{\text { Averagebid(excl.lowest })- \text { lowestbid }}{\text { lowestbid }}$ & 0.147 & & 0.202 & \\
\hline$\frac{2 \text { 2ndlowestbid-lowestbid }}{\text { lowestbid }}$ & 0.089 & & 0.140 & \\
\hline Observations & 345 & & 70 & \\
\hline
\end{tabular}

In 2009 prices, calculated for the cartel group also in the post-cartel period. Note that twelve observations with only one bid by a cartel member are excluded.

Bid per square meter is measured in Swedish Kronor (SEK) per square meter in the 2009 price level 
Table 2 Share of contracts per year, region and type of procurement procedure

\begin{tabular}{lrllll}
\hline \multicolumn{7}{l}{ Share per year } & \multicolumn{2}{l}{ Share per region } & \multicolumn{2}{l}{ Share per procedure } \\
\hline \multicolumn{7}{l}{ 1995-2001 } & & & \\
1995 & 0.208 & 1-North & 0.094 & Direct & 0.004 \\
1996 & 0.107 & 2-Middle & 0.004 & Negotiated & 0.012 \\
1997 & 0.096 & 3-Stockholm & 0.198 & Restricted & 0.017 \\
1998 & 0.183 & 4-Mälardalen & 0.180 & Open & 0.189 \\
1999 & 0.069 & 5-West & 0.298 & Simplified & 0.739 \\
2000 & 0.235 & 6-Southeast & 0.123 & Selective & 0.007 \\
2001 & 0.102 & 7-Skåne & 0.103 & Unknown & 0.032 \\
$2004-2009$ & & & & \\
2004 & 0.214 & 1-North & 0.541 & Direct & 0.040 \\
2005 & 0.140 & 2-Middle & 0.151 & Negotiated & 0.000 \\
2006 & 0.204 & 3-Stockholm & 0.000 & Restricted & 0.000 \\
2007 & 0.144 & 4-Mälardalen & 0.030 & Open & 0.027 \\
2008 & 0.214 & 5-West & 0.201 & Simplified & 0.933 \\
2009 & 0.084 & 6-Southeast & 0.054 & Selective & 0.000 \\
& & 7-Skåne & 0.023 & Unknown & 0.000 \\
\hline
\end{tabular}

lower sampling probability for the southern regions. As auctions with combinatorial bidding are excluded, no procurements from the Stockholm area are included in our data for the post-cartel period.

The regional population density, Dens $s_{r}$, is used to capture potential differences in transportation costs where the basic idea is that the distance between the construction site and the asphalt plant declines with population density. ${ }^{26}$ Dens may also reflect the degree of competition if one believes that the number of potential bidders increases with population density. In addition to regional and year fixed effects, annual average temperature $\left(\operatorname{Temp}_{r}\right)$ and average monthly rainfall $\left(\operatorname{Rain}_{r}\right)$, by region $r$, are included to capture regional conditions. Information on temperature and rainfall has been provided by SMHI.

\section{Econometric Setup and Empirical Approach}

Consider bidders of two types - type $A$ and type $B$ - that compete for contracts in procurement auctions where contracts are awarded to the lowest bidder. Bidders of type $A$ form a cartel, whereas bidders of type $B$ bid independently of each other. That is, bidding strategies are dependent among type $A$ bidders and are independent among type $B$ bidders as well as across the two types $A$ and $B$.

${ }^{26}$ During the period of study mobile asphalt plants where not common. 
Denote by $b_{i c}$ a bid that is placed by bidder $i$ on contract $c$. With a total of $n_{c}$ contracts and an average of $n_{A}+n_{B}$ bidders of type $A$ and $B$ on each contract, the total number of bids in the sample is $N=n_{c} \times\left(n_{A}+n_{B}\right)$. Consider three type $A$ bidders: $i, j$, and $l$. The strategy that is adopted among type $A$ bidders is such that only one type $A$ bidder-bidder $i$-places a low bid, $b_{i c}$, on contract $c$, while the rest of type $A$ bidders - $j$ and $l$-engage in complementary bidding and place high bids. ${ }^{27}$

Next, consider the regression equation

$$
b=\rho \mathbf{W} b+\mathbf{X} \boldsymbol{\beta}+\varepsilon
$$

where $b$ is the vector of all bids placed by both types of bidders for all observed auctions, $\mathbf{X}$ is a matrix of relevant covariates, $\varepsilon$ is an error component with the usual properties, and $\rho$ and $\boldsymbol{\beta}$ are parameters to be estimated. $\mathbf{W}$ is a matrix of dimension $(N \times N)$ with elements $w$ such that $w_{j c, l c}>0$, else $w=0$. In particular, $w_{i c, j k}=w_{j c, l k}=w_{i c, l k}=0$ if $c \neq k$, so that bids are conditionally independent between contracts (where $c$ and $k$ denote contracts) and $w_{i^{\prime} c, j^{\prime} c}=0$ if $i^{\prime} \in B$ and/or if $j^{\prime} \in B$, so that a non-colluding firm's bids will be independent of bids from all other bidders, whether of type $A$ or $B$.

Based on the definition of the elements of $\mathbf{W}$-in the spatial econometrics literature this is referred to as a spatial weights matrix - bidding strategies are by assumption independent among type $B$ bidders and across the two types of bidders, $A$ and $B$, whereas dependence is not ruled out between bidders of type $A$. Accordingly, and under the assumption that we have controlled for all information that is available to the bidders, $\rho \neq 0$ suggests that a bid placed by a cartel member (a bidder of type $A$ ) depends on bids that are placed by the other cartel members on the same contract. Note also that $w_{i c, i c}=0$ implies that the diagonal of $\mathbf{W}$ consists of zeros only; this assures that $b_{i c}$ will not depend on $b_{i c}{ }^{28}$ Moreover, even if we fail to control for some covariates, it is expected that $\rho_{\text {cartel }} \neq \rho_{\text {non-cartel }}$.

From Eq. (1) it is evident that the definition of the elements in $\mathbf{W}$ is of crucial importance and deserves special attention: As $\mathbf{W}$ is of dimension $(N \times N)$, it is not possible to estimate its elements together with the other parameters in the model. That is, it is not possible, for instance, to estimate the probability that firms $i, j$, and $l$ coordinate their bids.

Hence, $w_{j c, l c}$ has to be determined a priori based on some criterion that reflects the underlying theory. If we apply the simple bidding strategy that was discussed above and still assume that cartel member $i$ places the lowest bid among cartel members, $w_{j c, l c}>0$ for $j \neq l$, and $i, j, l \in A$; otherwise $w=0$.

It is, however, not obvious what value $w_{j c, l c}$ should take to reflect the connectedness or negotiation power between cartel members, and the theory gives no clear guidance on this matter. If we follow common practice in applied spatial econometrics, the weights matrix $\mathbf{W}$ is row standardized: The elements are defined such that $w_{j c, l c}=1 /\left(n_{A c}-1\right)$ where $n_{A c}$ is the number of type $A$ bidders on contract $c$. As the

\footnotetext{
27 This assumption is in line with the 2007 findings of the court on the asphalt cartel.

28 In the social networks literature, $w_{i c, i c}$ is typically not zero as all members are often allowed to affect the norm within the network.
} 
elements in $\mathbf{W}$ are nonnegative, this ensures that all of the weights are between 0 and 1.

As cartel member $i$ submits the lowest bid among the cartel members on contract $c$, then $w_{i c, j c}=w_{i c, l c}=0$, while $w_{l c, j c}>0$. This implies that $b_{i c}$ is not regressed on the bids placed by the other cartel members while $b_{l c}$ and $b_{j c}$ depend on each other. Hence, the correlation between the other cartel members' bids is expected to be positive. ${ }^{29}$ The direction of the dependence between $b_{l c}$ and $b_{j c}$ is not obvious, which makes $\mathbf{W} b$ endogenous in Eq. (1).

The regression Eq. (1) is often referred to as a spatial lag model, and it is well known from the spatial econometric literature that OLS estimates will be biased and inconsistent-irrespective of the property of the error term (see, for instance, Anselin 1988). Instead, maximum likelihood or different IV or GMM estimators are frequently used. One advantage with maximum likelihood is that the parameter space for $\rho$ is restricted to $\rho \leq|1|$, which is not generally the case for IV or GMM estimators; a drawback is that instrumenting for other potentially endogenous variables is not easily done (Elhorst 2014). ML is theoretically more efficient than GMM when data are normally distributed; but ML does not provide efficient estimates in the heteroscedastic case.

In the present paper, Eq. (1) is estimated by a GMM estimator that is known as the generalized two-stage least-squares estimator (GS2SLS) using the Stata command spivregress which produces consistent estimates also in the heteroscedastic case. $^{30}$

Based on the discussion above and the data set that was described in Sect. 4, the bid per square meter that is submitted by bidder $i$ on contract $c, b_{i c}$, is assumed to be determined by the function

$$
\begin{aligned}
b_{i c}= & \rho \mathrm{Wb}_{c}+\beta_{\text {Comp }} \times \text { Comp }_{c}+\beta_{\text {Dens }} \times \text { Dens }_{r} \\
& +\beta_{\text {Area }} \times \text { Area }_{c}+\beta_{\text {Temp }} \times \text { Temp }_{r}+\beta_{\text {Rain }} \\
& \times \text { Rain }_{r}+\alpha_{f}+\alpha_{r}+\alpha_{t}+\varepsilon_{\text {icr }}
\end{aligned}
$$

where $i=1, \ldots, N$; the $\alpha$ 's, $\rho$, and $\beta$ 's are parameters to be estimated, and $\varepsilon$ is an error term that is assumed to have the usual properties; $\alpha_{f}, \alpha_{r}$, and $\alpha_{t}$ are firm, regional, and time fixed effects, respectively.

Our interest lies in the parameter $\rho$, where $\rho>0$ and $\rho_{\text {cartel }} \neq \rho_{\text {non-cartel }}$ is taken as evidence for collusive bidding behavior among bidders that are defined as cartel members by $\mathbf{W}$. A significant difference between the estimated values of $\rho$ and/or in the variance in $\rho$ for the cartel-and post-cartel periods would also suggest a structural shift in bidding behavior between the two periods. In accordance with the court

\footnotetext{
${ }^{29}$ The use of the spatial weights matrix to calculate the average bid of the other cartel members is very convenient for data sets with many procurements and many (potential) cartel members.

${ }^{30}$ Dummy variables for the different procurement procedures are used as instruments and the model is estimated using the GS2SLS estimator (the spivregress command in Stata) that was derived by Kelejian and Prucha (1998, 1999, 2010) and extended by Arraiz et al. (2010) and Drukker et al. (2013).
} 
order, it is assumed that the cartel consists of the nine convicted and fined firms only. $^{31}$

As the linear functional form of Eq. (2) might be too restrictive, for comparison, the alternative logarithmic specification is estimated

$$
\begin{aligned}
\ln \left(b_{i c}\right)= & \rho W \ln \left(b_{c}\right)+\beta_{\ln \text { Comp }} \times \ln \left(\text { Comp }_{c}\right)+\beta_{\ln \text { Dens }} \times \ln \left(\text { Dens }_{r}\right) \\
& +\beta_{\ln \text { Area }} \times \ln \left(\text { Area }_{r}\right)+\beta_{\ln \text { Temp }} \times \ln \left(\text { Temp }_{r}\right) \\
& +\beta_{\ln \text { Rain }} \times \ln \left(\text { Rain }_{r}\right)+\alpha_{f}+\alpha_{r}+\alpha_{t}+\varepsilon_{\text {ic }}
\end{aligned}
$$

The estimation strategy is to estimate different versions of Eq. (2) and (3) separately: first for the cartel period only (1995-2001); then for the post-cartel period only (2003-2009); and finally for the pooled the data (1995-2001 and 2003-2009). For the cartel period $\rho>0$ indicates collusive bidding behavior, while $\rho=0$ for the post-cartel period suggests conditional independence across bids by cartel members. The pooled dataset is used to address the potential concern that a positive and significant parameter estimate of $\rho$ for the cartel period is just picking up the effect of unobserved (to us) heterogeneity between the different contracts. To test for a structural shift in bidding behavior among (former) cartel members, the dataset is pooled, and a test of the hypothesis that $\rho_{\text {cartel }} \neq \rho_{\text {post-cartel }}$ is based on

$$
\begin{aligned}
b_{\text {ic }}= & \rho_{\text {post-cartel } W_{\text {DD }}+\rho_{\text {cartel }} W_{c}+\beta_{\text {DComp }} \times D \times \text { Comp }_{c}+\beta_{\text {Comp }}} \\
& \times \text { Comp }_{c}+\beta_{\text {Dens }} \times \text { Dens }_{r}+\beta_{\text {Area }} \times \text { Area }_{r} \\
& +\beta_{\text {Temp }} \times \text { Temp }_{r}+\beta_{\text {Rain }} \times \text { Rain }_{r}+\alpha_{f}+\alpha_{r}+\alpha_{t}+\varepsilon_{i c}
\end{aligned}
$$

where $D=1$ for the post-cartel period; otherwise $D=0$. Note that separate parameters are estimated for Comp, as it is reasonable to expect the effect of the number of bidders to differ between the cartel period and the post-cartel period.

\section{Results}

First consider parameter estimates for different specifications of Eqs. (2) and (3) for the cartel period displayed in Table 3. In Table 3, columns GMM1, GMM2 and GMM5 correspond to linear specifications with and without the variable Comp, and GMM3, GMM4 and GMM6 correspond to log-linear specifications. $F$-tests are carried out to test for the joint significance of the three sets of dummy variables; firm fixed effects, regional fixed effects, and time fixed effects. As the $F$-test for inclusion of firm fixed effects in columns GMM1 and GMM2 suggests that the firm fixed effects does not contribute to the model, the model has been

\footnotetext{
31 According to the SCA (2009), other firms were affected by the cartel and might have bid non-competitively because the cartel offered them side payments or sub-contracts; but we cannot be certain when and for which firms this happened. Indirectly, all firms may have been affected to the extent that the cartel succeeded in reducing competitive pressure.
} 


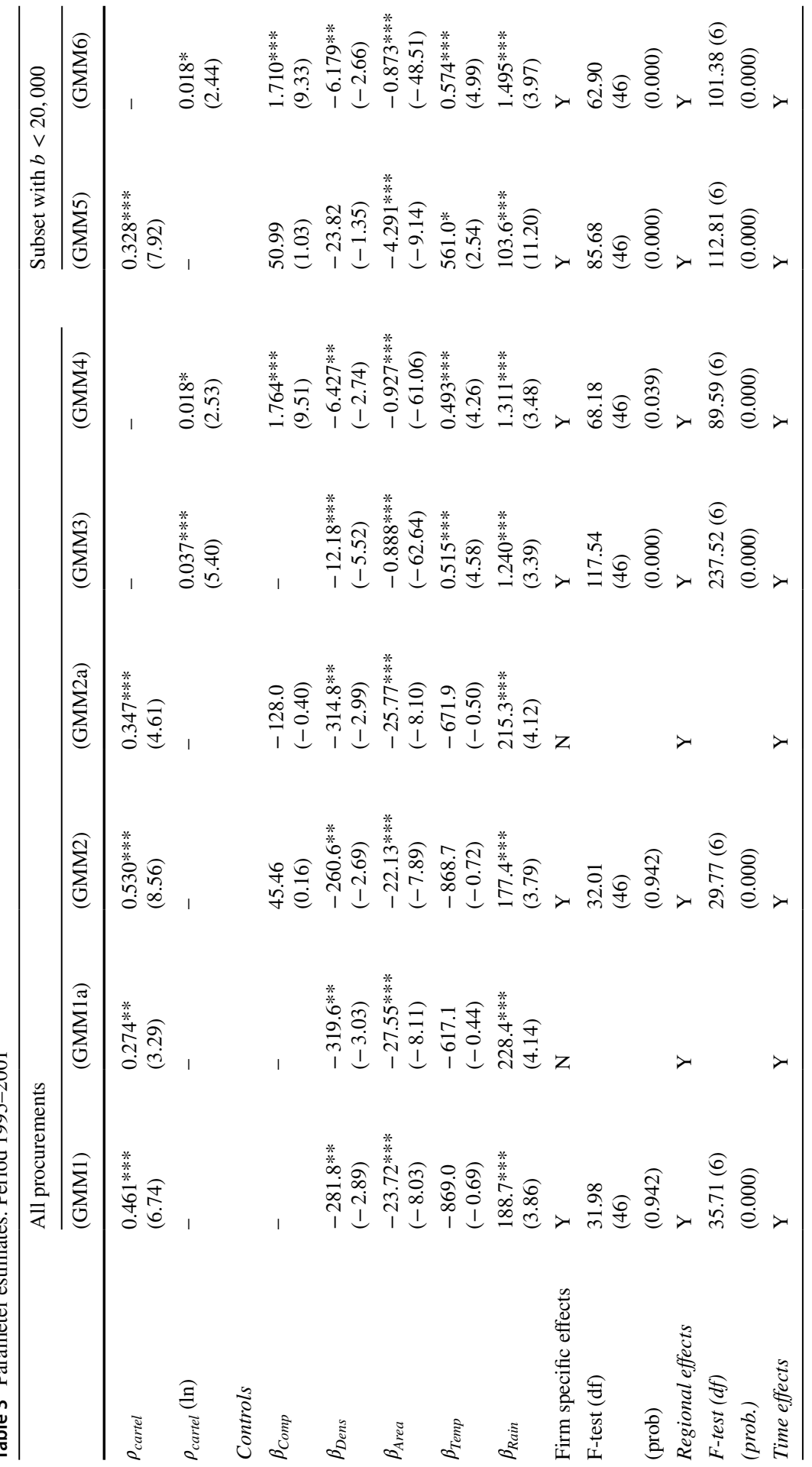




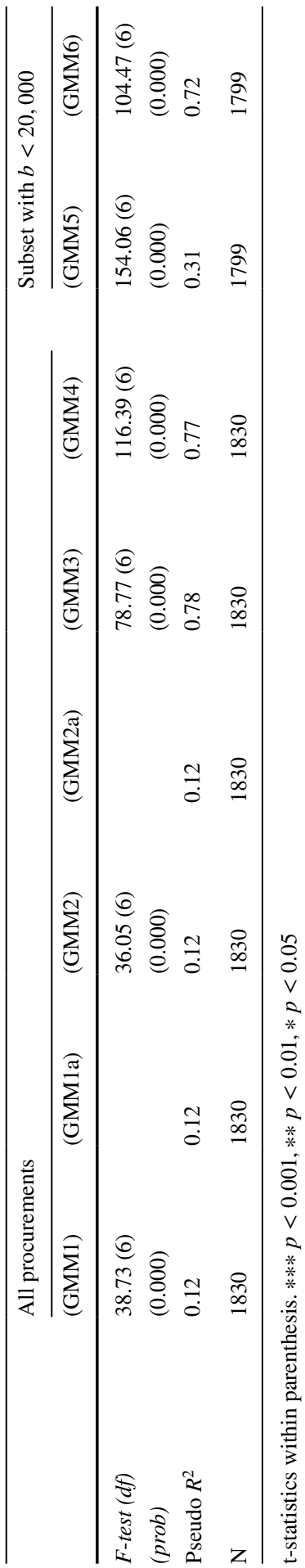


re-estimated without these fixed effects. The results are presented in columns GMM1a and GMM2a. Our main findings are not affected by the exclusion of the firm fixed effects. In columns GMM5 and GMM6 extreme observations of $b>20,000$ are excluded.

For the cartel period, $\rho$ is expected to be significant and positive, which is also the case in all specifications. This suggests that, between 1995 and 2001, the bids that were placed by the nine companies that were convicted by the Stockholm District Court for collusive bidding behavior on public contracts violated the conditional independence criteria, which is one of two conditions for statistical independence across bids. Hence, it is not possible to rule out the possibility of coordinated bidding among cartel firms that were designated not to win the contract and that the parameter $\rho$ picks up collusive bidding.

When we briefly turn to the other covariates, the two measures that are included to reflect the market structure-Comp and Dens-are expected have a negative impact on $b$. For all specifications, Dens is estimated to have a negative effect on $b$ during this period. If Dens reflects the degree of competition, this is in line with expectations: Higher potential competition should result in lower bids. However, Dens may also reflect transportation costs as it is reasonable to expect transportation costs to be lower in more densely populated areas. As it turns out, the effect of the number of bidders, Comp, on $b$ is insignificant in the linear specification, and positive and significant in the logarithmic specification. A possible explanation for this result is that the coefficient captures the complementary bidding behavior of the cartel members or the attractiveness of a highly profitable collusive market for new entrants. Moreover, for the logarithmic specification, the inclusion of Comp makes the point estimate of Dens smaller.

The variable Area is included to capture potential project-based economies of scale and therefore expected to have a negative effect on $b$. The presence of economies of scale is confirmed by the negative correlation between Area and $b$ presented in Table 3. Both temperature (Temp) and rain (Rain) are, when significant, estimated to have a positive effect on $b$. We return to the interpretation of these findings below.

The positive and significant parameter estimate of $\rho$ displayed in Table 3 indicates that the proposed econometric setup can detect suspicious bidding behavior during the cartel period. Parameter estimates that correspond to the post-court-order period after 2003, displayed in Table 4, indicate a non-significant correlation between bids placed by (former) cartel members on public contracts. Based on these estimates it is not possible to reject the hypothesis that, between 2004 and 2009, bids that were placed by the convicted companies meet the conditional independence criterion. This allows us to conclude that, at least based on the present dataset, the proposed method is capable of both identifying collusive bidding behavior when such behavior has been verified by court order and rejecting conditional dependence in cases where such behavior is not likely to be present.

For all of the models that are presented in Table 4 , the $F$-tests for the joint significance of the three sets of dummy variables suggest that one or more of the sets of fixed effects are not collectively significant. In those cases, the model is re-estimated without that particular set of fixed effects; see columns GMM1a-GMM6a. As $\rho<0$ in columns GMM1a to GMM6a, the exclusion of irrelevant fixed effects 


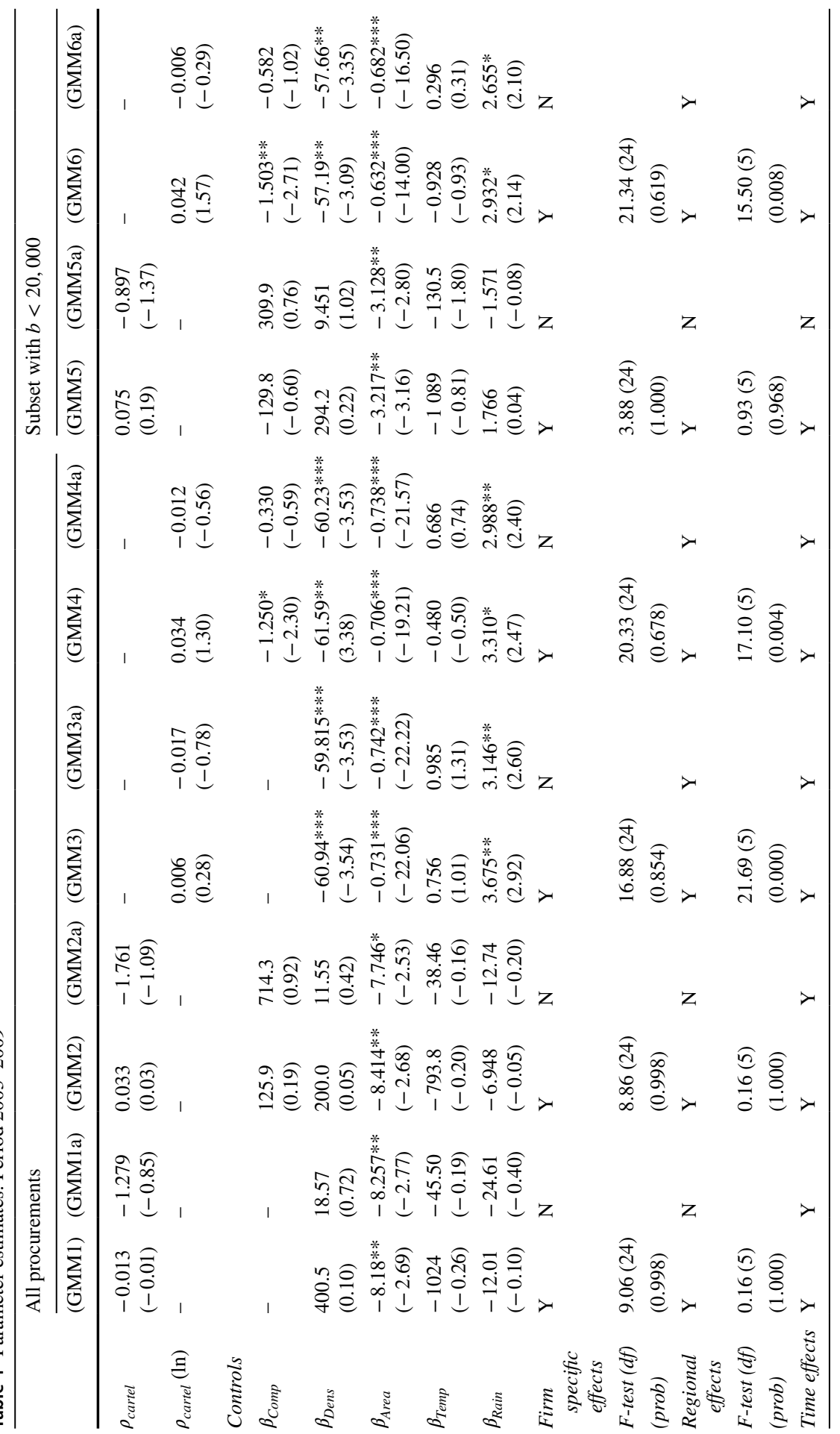




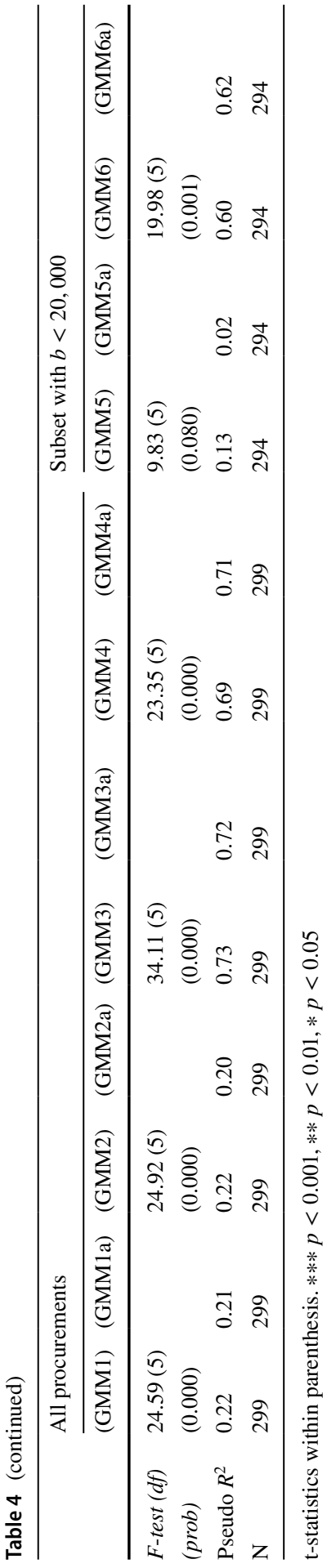


strengthens our previous conclusion. However, even though $\rho$ is negative in those models, $\rho$ is still insignificant. Moreover, in two models-GMM1a and GMM2a$\rho<-1$, which indicates that the system is unstable.

When we examine the other covariates, in contrast with the cartel period the results indicate a negative relation between Comp and $b$ in the logarithmic specifications. This result is of special interest as it is consistent with the interpretation of complementary bidding during the cartel period. However, in contrast with the cartel period, Dens alters sign and varies in significance across the different specifications. Area is again estimated to have a negative impact on $b$, which indicates the presence of project-based economies of scale also for the post-cartel period.

For the post-cartel period, rain (Rain) remains significant, while there is no significant effect of temperature (Temp) on $b$. There are several possible interpretations for these results: Temperature has a north-south dimension with lower average temperatures in northern and mountainous regions. The lower population density in these regions could result in lower costs per surface area, but another possible explanation is that the cartel had a stronger influence on the bids in the southern parts of the country.

The results so far suggest that the conditional-independence-across-bids criterion was violated during the cartel period but not during the post-cartel period. Next, we pool the two periods into one to test for a structural break in bidding behavior between the cartel and post-cartel periods. Parameter estimates and corresponding $t$-values are presented in Table 5 .

First, the results suggest that $\rho_{\text {cartel }}$ is positive and significant in all models, while $\rho_{\text {non-cartel }}$ is insignificant with a sign that alternates across models. This is in line with our previous findings in Tables 3 and 4 . A one-sided $z$-test, displayed at the bottom of Table 5, supports the hypothesis that $\rho_{\text {cartel }}>\rho_{\text {non-cartel }}$ at the 95 percent level of significance in the linear specification and at the 90 percent level in the other specifications. ${ }^{32}$ This is of interest as a significant difference between the estimated $\rho$ for two periods addresses the potential concern that a positive and significant parameter estimate is just picking up the effect of unobserved (to us) heterogeneity between the different contracts. Such heterogeneity could induce a positive estimate for $\rho$. Moreover, an $F$-test, also displayed in the bottom part of Table 5, indicates a significant shift in variance $\left(\sigma^{2}\right)$ in $\rho$ between the two periods. The $F$-tests for firm, regional, and time fixed effects all indicate each set of fixed effects to be jointly significant.

\section{Conclusions}

The aim of this paper has been to present how an econometric setup that is inspired by the spatial econometric literature can be used to detect non-independent bidding between potential cartel members. The method is applied to the well-documented

32 The $z$-statistic is calculated as $z=\left(\rho_{\text {cartel }}-\rho_{\text {post-cartel }}\right) /\left(\left(S E\left(\rho_{\text {cartel }}\right)\right)^{2}+\left(S E\left(\rho_{\text {post-cartel }}\right)\right)^{2}\right)^{0.5}$; see Clogg et al. (1995), Paternoster et al. (1998) and Brame et al. (1998). The $F$-statistic is calculated as $\sigma_{\text {non-cartel }}^{2} / \sigma_{\text {cartel }}^{2}$ 
Table 5 Parameter estimates. Period 1995-2009

\begin{tabular}{|c|c|c|c|c|}
\hline & \multicolumn{2}{|c|}{ All procurements } & \multicolumn{2}{|c|}{ Subset with $b<20,000$} \\
\hline & (GMM 1) & (GMM 2) & (GMM 3) & (GMM 4) \\
\hline$\rho_{\text {cartel }}$ & $\begin{array}{l}0.615 * * * \\
(5.18)\end{array}$ & - & $\begin{array}{l}0.492 * * * \\
(7.76)\end{array}$ & - \\
\hline$\rho_{\text {non-cartel }}$ & $\begin{array}{l}-0.873 \\
(-1.15)\end{array}$ & - & $\begin{array}{l}0.065 \\
(0.21)\end{array}$ & - \\
\hline$\rho_{\text {cartel }}(\ln )$ & - & $\begin{array}{l}0.029 * * * \\
(3.79)\end{array}$ & - & $\begin{array}{l}0.029 * * * \\
(3.65)\end{array}$ \\
\hline$\rho_{\text {non-cartel }}(\ln )$ & - & $\begin{array}{l}-0.013 \\
(-0.45)\end{array}$ & - & $\begin{array}{l}-0.008 \\
(-0.30)\end{array}$ \\
\hline \multicolumn{5}{|l|}{ Controls } \\
\hline$\beta_{\text {Comp }, 1995-2001}$ & $\begin{array}{l}-17.73 \\
(-0.12)\end{array}$ & $\begin{array}{l}1.614 * * * \\
(7.63)\end{array}$ & $\begin{array}{l}-17.29 \\
(-0.41)\end{array}$ & $\begin{array}{l}1.557 * * * \\
(7.47)\end{array}$ \\
\hline$\beta_{\text {Comp }, 2003-2009}$ & $\begin{array}{l}219.19 \\
(0.81)\end{array}$ & $\begin{array}{l}-2.233 * * * \\
(-4.66)\end{array}$ & $\begin{array}{l}63.82 \\
(0.64)\end{array}$ & $\begin{array}{l}-2.160 * * * \\
(-4.60)\end{array}$ \\
\hline$\beta_{\text {Dens,1995-2009 }}$ & $\begin{array}{l}-213.1 * * \\
(-3.11)\end{array}$ & $\begin{array}{l}-10.91 * * * \\
(-4.63)\end{array}$ & $\begin{array}{l}-30.09 \\
(-1.56)\end{array}$ & $\begin{array}{l}-10.68 * * * \\
(-4.55)\end{array}$ \\
\hline$\beta_{\text {Area }, 1995-2009}$ & $\begin{array}{l}-16.78 * * * \\
(-4.46)\end{array}$ & $\begin{array}{l}-0.892 * * * \\
(-56.34)\end{array}$ & $\begin{array}{l}-4.257 * * * \\
(-6.97)\end{array}$ & $\begin{array}{l}-0.839 * * * \\
(-47.21)\end{array}$ \\
\hline$\beta_{\text {Temp,1995-2009 }}$ & $\begin{array}{l}-131.6 \\
(-0.20)\end{array}$ & $\begin{array}{l}0.642^{* * * *} \\
(6.39)\end{array}$ & $\begin{array}{l}729.0 * * * \\
(5.16)\end{array}$ & $\begin{array}{l}0.718 * * * \\
(7.25)\end{array}$ \\
\hline$\beta_{\text {Rain,1995-2009 }}$ & $\begin{array}{l}131.0 * * * \\
(3.58)\end{array}$ & $\begin{array}{l}1.289^{* * * *} \\
(4.04)\end{array}$ & $\begin{array}{l}48.38 * * * \\
(5.89)\end{array}$ & $\begin{array}{l}1.318^{* * * *} \\
(4.19)\end{array}$ \\
\hline Firm specific effects & $\mathrm{Y}$ & $\mathrm{Y}$ & $\mathrm{Y}$ & $\mathrm{Y}$ \\
\hline$F$-test $(d f)$ & $6873(52)$ & $9833(52)$ & $39,463(52)$ & $8667(52)$ \\
\hline$($ prob $)$ & $(0.000)$ & $(0.000)$ & $(0.000)$ & $(0.000)$ \\
\hline Regional effects & $\mathrm{Y}$ & $\mathrm{Y}$ & $\mathrm{Y}$ & $\mathrm{Y}$ \\
\hline$F$-test $(d f)$ & $15.61(6)$ & $103.39(6)$ & $58.45(6)$ & $121.28(6)$ \\
\hline$($ prob $)$ & $(0.016)$ & $(0.000)$ & $(0.000)$ & $(0.000)$ \\
\hline Time effects & $\mathrm{Y}$ & $\mathrm{Y}$ & $\mathrm{Y}$ & $\mathrm{Y}$ \\
\hline$F$-test $(d f)$ & $28.75(12)$ & $192.46(12)$ & $73.72(12)$ & $189.26(12)$ \\
\hline$($ prob $)$ & $(0.004)$ & $(0.000)$ & $(0.000)$ & $(0.000)$ \\
\hline$z$-test of $\rho_{\text {cartel }}>\rho_{\text {non-cartel }}$ & $\begin{array}{l}1.94 \\
(p \text { value } 0.026)\end{array}$ & $\begin{array}{l}1.43 \\
(p \text { value } 0.076)\end{array}$ & $\begin{array}{l}1.35 \\
(p \text { value } 0.089)\end{array}$ & $\begin{array}{l}1.38 \\
(p \text { value } 0.084)\end{array}$ \\
\hline$F$-test of $\sigma_{\text {cartel }}^{2} \neq \sigma_{\text {non-cartel }}^{2}$ & $\begin{array}{l}41.59 \\
(p \text { value } 0.000)\end{array}$ & $\begin{array}{l}12.25 \\
(p \text { value } 0.000)\end{array}$ & $\begin{array}{l}24.21 \\
(p \text { value } 0.000)\end{array}$ & $\begin{array}{l}12.25 \\
(p \text { value } 0.000)\end{array}$ \\
\hline Pseudo $R^{2}$ & 0.12 & 0.76 & 0.25 & 0.71 \\
\hline $\mathrm{N}$ & 2129 & 2129 & 2093 & 2093 \\
\hline
\end{tabular}

t-statistics within parenthesis. $* * * p<0.001, * * p<0.01, * p<0.05$

Swedish asphalt cartel, for which we have data from the cartel period as well as for the post-cartel period. The method confirms a significant and positive correlation between non-winning cartel members' bids during the cartel period, which suggests complementary bidding by these firms in order to maintain the appearance of a competitive market. 
When we apply the same method to the post-cartel period, no indication of complementary bidding is detected. Hence, our results suggest that the method is capable of identifying an active cartel, while not indicating collusive behavior during a period when such behavior is likely not to have occurred. The parameter estimates of interest and its variance also differ in magnitude between the two periods, which indicates a structural change in bidding behavior among cartel members subsequent to cartel discovery.

Extending the model with additional firm characteristics, geographic information (such as the geographic distance between firms), and local and regional characteristics (such as political preferences that reflect the attitude towards public investments and taxes, local labor market conditions, etc.) could potentially improve its performance. More information could help control for potential heterogeneity across type A and B bids on the same contract or between-contract heterogeneity. However, we have chosen not to do so because the main purpose has been to test and describe a simple method to be used for (fast) screening of many different markets and procurements for potentially suspicious bidding behavior, given the aim of finding a statistical method that can be used for cartel detection with a minimum of information: in this case, the bids only.

The main merit of the suggested approach is hence its simplicity and its relatively small data requirements. If there is suspicion of collusive behavior in a particular market or during a particular time period, the proposed method could be used by, for example, competition authorities to test for conditional independence in bidding by firms that are suspected to collude and, in this way, contribute to the verification of the cartel.

The method is potentially difficult to use for cartel scanning in markets with low concentration and no obvious set of suspected conspirators. As the number of firms grows, a multiple-testing problem arises, since the number of possible cartel combinations in a cartel of unknown size increases quickly: from four in a three-firm industry to 26 when there are five firms and to 247 when there are eight. However, most cartels seem to occur in concentrated industries, have relatively few members, and consist of large firms. ${ }^{33}$ Furthermore, competition authorities often have relatively strong priors as to the identity of the cartel's members. In such settings, the proposed method can be used for scanning within a limited set of possible cartel combinations, or for verifying suspicions.

In brief, we conclude that the suggested method appears to be capable of identifying cartels and has the potential to serve as an initial screen for collusive behavior in auctions.

Acknowledgements We are most thankful for thoughtful and very constructive comments from Lawrence White (the editor) which have significantly improved the quality and focus of the article. We also thank two anonymous referees for their helpful comments and suggestions as well as seminar participants at Umeå University, Södertörn University, The Spatial Econometrics annual meeting in New York, The North American Regional Science Councils annual meeting in Washington, and at the Swedish

\footnotetext{
${ }^{33}$ Levenstein and Suslow (2016) report that, in a sample of 195 bid-rigging cartels, the mean (median) number of members is $5.2(3)$.
} 
Competition Authority in Stockholm. Financial support from the Swedish Competition Authority is acknowledged and we are grateful to Maria Jakobsson for generouslly sharing data with us. Remaining errors are the sole responsibility of the authors.

Open Access This article is distributed under the terms of the Creative Commons Attribution 4.0 International License (http://creativecommons.org/licenses/by/4.0/), which permits unrestricted use, distribution, and reproduction in any medium, provided you give appropriate credit to the original author(s) and the source, provide a link to the Creative Commons license, and indicate if changes were made.

\section{References}

Abrantes-Metz, R., \& Bajari, P. (2009). Screens for conspiracies and their multiple applications. Antitrust, 24(1), 66-71.

Abrantes-Metz, R., Froeb, L. M., Geweke, J., \& Taylor, C. (2006). A variance screen for collusion. International Journal of Industrial Organization, 24(3), 467-486.

Anselin, L. (1988). Spatial econometrics: Methods and models. Dordrecht: Kluwer Academic Publisher.

Anselin, L. (2003). Spatial econometrics. In B. H. Baltagi (Ed.), A companion to theoretical econometrics (pp. 310-330). Oxford: Blackwell.

Anselin, L., \& Bera, A. (1998). Spatial dependence in linear regression models with an introduction to spatial econometrics. In A. Ullah \& D. Giles (Eds.), Handbook of applied economics statistics (pp. 237-289). New York: Marcel Dekker.

Arraiz, I., Drukker, D. M., Kelejian, H. H., \& Prucha, I. R. (2010). A spatial Cliff-Ord-type model with heteroskedastic innovations: Small and large sample results. Journal of Regional Science, 50, 592-614.

Bajari, P., \& Summers, G. (2002). Detecting collusion in procurement auctions. Antitrust Law Journal, 70(1), 143-170.

Bajari, P., \& Ye, L. (2003). Deciding between competition and collusion. The Review of Economics and Statistics, 85(4), 971-989.

Bergman, M. A., \& Lundberg, S. (2013). Tender evaluation and supplier selection methods in public procurement. Journal of Purchasing and Supply Management, 19(2), 73-83.

Börgers, T., \& van Damme, E. (2004). Auction theory for auction design. In M. Janssen (Ed.), Auctioning public assets: Analysis and alternatives. Cambridge: Cambridge University.

Bound, J., Jaeger, D. A., \& Baker, R. (1993). The cure can be worse than the disease: A cautionary tale regarding instrumental variables. NBER technical working paper no. 137.

Bound, J., Jaeger, D. A., \& Baker, R. (1995). Problems with instrumental variables estimation when the correlation between the instruments and the endogenous explanatory variables is weak. Journal of the American Statistical Association, 90(430), 443-450.

Brame, R., Paternoster, R., Mazerolle, P., \& Piquero, A. (1998). Testing for the equality of maximum likelihood regression coefficients between two independent equations. Journal of Quantitative Criminology, 14(3), 245-261.

Che, Y.-K. (1993). Design competition through multidimensional auctions. RAND Journal of Economics, 24(4), 668-680.

Clogg, C. C., Petkova, E., \& Haritou, A. (1995). Statistical methods for comparing regression coefficients between models. American Journal of Sociology, 100(5), 1261-1293.

Conley, T. G., \& Decarolis, F. (2016). Detecting bidders groups in collusive auctions. American Economic Journal: Microeconomics, $8(2), 1$.

Cramton, P., \& Schwartz, J. A. (2000). Collusive bidding: Lessons from the FCC spectrum auctions. Journal of Regulatory Economics, 17(3), 229-252.

Cramton, P., \& Schwartz, J. A. (2002). Collusive bidding in the FCC spectrum auctions. Contributions to Economic Analysis and Policy, 1(1), 11.

Directive 2004/17/EC of the European Parliament and of the Council of 31 March 2004 coordinating the procurement procedures of entities operating in the water, energy, transport and postal services sectors $(30.04 .2004)$ 
Directive 2014/24/EU on the European Parliament and of the Council of 26 February 2014 on public procurement and repealing Directive 2004/18/EC.

Directive 2014/25/EU of the European Parliament and of the Council of 26 February 2014 on procurement by entities operating in the water, energy, transport and postal services sectors and repealing Directive 2004/17/EC.

Doane, M. J., Froeb, L. M., Pinto, B. J., \& Sibley, D. S. (2014). Screening for collusion as a problem of inference. In D. Sokol (Ed.), Oxford handbook of international antitrust economics (pp. 523-553). Kettering: Oxford University Press.

Drukker, D. M., Egger, P. H., \& Prucha, I. R. (2013). On two-step estimation of a spatial autoregressive model with autoregressive disturbances and endogenous regressors. Econometric Reviews, 32, 686-733.

Elhorst, J. P. (2014). Spatial econometrics. From cross-sectional data to spatial panels. Heidelberg: Springer.

Froeb, L. M., Koyak, R. A., \& Werden, G. J. (1993). What is the effect of bid rigging on prices? Economics Letters, 42, 419-423.

Gibbons, S., Overman, H. G., \& Patacchini, E. (2015). Spatial methods. In G. Duranton, J. V. Henderson, \& W. Strange (Eds.), Handbook of regional and urban economics (Vol. 5, pp. 115-168). Amsterdam: Elsevier.

Grout, P., \& Sonderegger, S. (2005). Predicting cartels. OFT Research Paper 773, Office of Fair Trading, London.

Gupta, S. (2001). The effect of bid rigging on prices: A study of the highway construction industry. Review of Industrial Organization, 19(4), 453-467.

Gupta, S. (2002). Competition and collusion in a government procurement auction market. Atlantic Economic Journal, 30(1), 13-25.

Harrington, J. E. (2008). Detecting cartels. In P. Buccirossi (Ed.), Handbook of antitrust economics (Vol. 1). London: MIT Press.

Heijnen, P., Haan, M. A., \& Soetevent, A. R. (2015). Screening for collusion. A spatial statistics approach. Journal of Economic Geography, 15(2), 417-448.

Ishii, R. (2009). Favour exchange in collusion: Empirical study of repeated procurement auctions in Japan. International Journal of Industrial Organization, 27(2), 137-144.

Jakobsson, M. (2007a). Bid-rigging in Swedish procurement auctions. Mimeo: Department of Economics, Uppsala University, Sweden.

Jakobsson, M. (2007b). Collusion in procurement auctions: A structural estimation. Mimeo: Department of Economics, Uppsala University, Sweden.

Kawai, K., \& Nakabayashi, J. (2014). Detecting large-scale collusion in procurement auctions. (May 28, 2014). Available at SSRN: http://ssrn.com/abstract=2467175 or http://dx.doi.org/10.2139/ ssrn.2467175.

Kelejian, H. H., \& Prucha, I. R. (1998). A generalized spatial two-stage least squares procedure for estimating a spatial autoregressive model with autoregressive disturbances. Journal of Real Estate Finance and Economics, 17, 99-121.

Kelejian, H. H., \& Prucha, I. R. (1999). A generalized moments estimator for the autoregressive parameter in a spatial model. International Economic Review, 40, 509-533.

Kelejian, H. H., \& Prucha, I. R. (2010). Specification and estimation of spatial autoregressive models with autoregressive and heteroskedastic disturbances. Journal of Econometrics, 157, 53-67.

Lee, I. K. (1999). Non-cooperative tacit collusion, complementary bidding and incumbency premium. Review of Industrial Organization, 15(2), 115-134.

Lee, I. K., \& Hahn, K. (2002). Bid-rigging in auctions for Korean public-works contracts and potential damage. Review of Industrial Organization, 21(1), 73-88.

LeSage, J. P., \& Pace, R. K. (2009). Introduction to spatial econometrics. Boca Raton: CRC Press.

Levenstein, M. C., \& Suslow, V. Y. (2016). Price fixing hits home: An empirical study of US price-fixing conspiracies. Review of Industrial Organization, 48(4), 361-379.

Lunander, A., \& Lundberg, S. (2013). Bids and costs in combinatorial and non-combinatorial procurement auctions. Evidence from procurement of public cleaning contracts. Contemporary Economic Policy, 31(4), 733-745.

Lundberg, S. (2005). Restrictions on competition in municipal competitive procurement in Sweden. International Advances in Economic Research, 11(3), 353-366.

Paternoster, R., Brame, R., Mazerolle, P., \& Piquero, A. (1998). Using the correct statistical test for the equality of regression coefficients. Criminology, 36(4), 859-866. 
Pesendorfer, M. (2000). A study of collusion in first-price auctions. Review of Economic Studies, 67(3), $381-411$.

Porter, R. H., \& Zona, J. D. (1993). Detection of bid rigging in procurement auctions. Journal of Political Economy, 101(3), 518-538.

Porter, R. H., \& Zona, J. D. (1999). Ohio school milk markets: An analysis of bidding. RAND Journal of Economics, 30(2), 263-288.

Robinson, M. S. (1985). Collusion and the choice of auction. RAND Journal of Economics, 16(1), $141-145$.

Swedish Competition Authority (SCA). (2009). Bakgrundsmaterial asfaltskartellen, 2009-05-28, Mimeo. In Swedish. Downloadable from www.kkv.se [In Swedish].

Publisher's Note Springer Nature remains neutral with regard to jurisdictional claims in published maps and institutional affiliations. 